\title{
Universidad Agropecuaria para Daule, Santa Lucía y Salitre, provincia del Guayas, Ecuador
}

\section{Agricultural University for Daule, Santa Lucía and Salitre, province of Guayas, Ecuador}

\author{
Mery Barzola Jiménez 1 https://orcid.org/0000-0002-4928-3326 \\ ${ }^{1}$ Escuela Superior Politécnica del Litoral, Guayaquil, Ecuador \\ mbarzoladespol.edu.ec
}

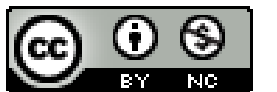

Esta obra está bajo una licencia internacional Creative Commons Atribución-NoComercial 4.0. $\begin{array}{ll}\text { Enviado: } & 2021 / 07 / 11 \\ \text { Aceptado: } & 2021 / 09 / 21 \\ \text { Publicado: } & 2021 / 12 / 30\end{array}$

\section{Resumen}

El propósito de este artículo es exponer una problemática que, desde hace más de treinta años, viene siendo una constante en los cantones de Daule, Santa Lucía y Salitre (provincia del Guayas - litoral ecuatoriano-). La investigación utilizó una metodología descriptiva con enfoque cualitativo, que permitió la descripción de un contexto rural agrícola desprovisto de créditos blandos para cultivos o de una forma asociativa que cree liderazgos; esto sin olvidar que los actores agrícolas no poseen las capacidades requeridas ni para negociar ante las autoridades gubernamentales ni para predecir anormalidades producto del cambio climático, y que quienes forman parte de la estructura familiar carecen de oportunidades laborales y de recursos económicos. Al explorar la raíz del problema, se pone de manifiesto la limitada preparación académica de los jóvenes debido a la ausencia de una infraestructura universitaria en carreras agropecuarias cercana a sus territorios, lo cual impide potenciar el desarrollo integral que el mercado laboral y la sociedad exigen de ellos. De ahí que se plantee implementar cinco objetivos del Plan Nacional de Desarrollo 2017-2021 en la zona de los tres cantones señalados, en colaboración con otros actores clave, para lograr un desarrollo económico sostenible. Los resultados obtenidos, a través de la aplicación de un cuestionario a una muestra no probabilística, reflejan tanto la necesidad de contar con una universidad que permita a los jóvenes de la región, que aún esperan una oportunidad, transformar sus vidas como la de mejorar la productividad de ese sector de la economía.

Palabras clave: agricultura, educación, jóvenes, rural, sostenibilidad. 


\begin{abstract}
The purpose of this article is to expose a thirty-year-old problem in the cantons of Daule, Santa Lucía, and Salitre in the province of Guayas, on the Ecuadorian coast. The descriptive research with a qualitative approach methodology describes a rural agricultural environment with a lack of soft credits for crops, absence of associativity to create leadership, inability to negotiate with government authorities, inability to predict abnormalities due to climate change, etc., associated with an absence of opportunities and economic resources of those who are part of the farming family. The root of the problem is the limited academic preparation of young people due to the shortage of university infrastructure in agricultural careers close to their territories, which does not allow them to enhance the integral development of young people that the labor market and society demand. To this end, five objectives of the National Development Plan 2017-2021 are proposed to be implemented in these three cantons plus the management of other key actors to achieve sustainable economic development. The results were obtained through a questionnaire to a non-probabilistic sample and reflect the need for this university, which is seen with the optimism of young people who are still awaiting an opportunity to transform their lives and the productivity of this economic sector.
\end{abstract}

Keywords: Agriculture, Education, Youth, Rural, Sustainability.

\title{
Introducción
}

Entre los años 1975 y 1981, un niño o joven rural del recinto Laurel, cantón Daule, de la provincia del Guayas, tenía el privilegio de crecer en un bello paisaje campesino circundado de verdes arrozales, de pintorescos árboles amarillos de dulce mango entre los meses de octubre a diciembre, de frejoles y hortalizas de ciclo corto, de animales de granja: en suma, en un entorno característico de la costa ecuatoriana. Podía además ser testigo en invierno de las subidas y en verano de las bajadas de los niveles fluviales del Pula, alimentarse con sus peces y bañarse en sus cristalinas aguas.

Quien recibió educación primaria en el sector rural por el año 1986 conoció de cerca el largo trayecto que a diario los profesores que venían de la ciudad al campo salvaban para impartir sus clases, el mal estado de las vías de acceso y de los caminos vecinales, la escasez de profesores locales, la modalidad de las escuelas unidocentes o plurigrados, cuya infraestructura era insuficiente y adolecía de falta de mantenimiento; todo lo cual repercutía en la calidad del proceso de aprendizaje.

De la misma manera, los contenidos de los programas educativos de las zonas rurales de América Latina, según Gajardo (2014), obedecen a parámetros curriculares de vigencia nacional que tienden a expresar valores urbanos, pues "no contemplan ni la realidad ni las necesidades del entorno local, ni los ciclos de producción agrícola" (p. 17). De estos ciclos se encargan los grupos familiares a fin de asegurar su subsistencia. Como complemento de lo señalado por Gajardo, Corvalán (2016) advierte sobre la necesidad de una política pública encaminada a subsanar la ausencia histórica de un sistema escolar que cuente con un currículo pertinente y apropiado para los sectores rurales latinoamericanos.

Entre los años 1986-1989, asistir al Ciclo Básico de un colegio público del cantón Daule, para un joven proveniente del ese entonces recinto Laurel (hoy, parroquia), implicaba tomar dos unidades de transporte público y hacer un trayecto de 50 minutos. El deseo de estudiar y superarse comportaba sacrificios económicos y riesgos físicos por las condiciones de transporte en aquella época. 
Posteriormente, entre 1990 y 1992, la búsqueda de la excelencia, para este mismo joven de Laurel, que en aquel momento deseaba cursar su bachillerato en la ciudad de Guayaquil, suponía disponer de los recursos económicos suficientes que le permitieran cubrir los gastos de hospedaje, alimentación, transportación urbana y cualquier otro similar en el puerto principal.

El estudio Juventud rural y empleo decente en América Latina (FAO, 2016), que describe la situación de los jóvenes rurales durante las décadas de 1980 y 1990, afirma que casi 20 millones de habitantes del campo migraron hacia las zonas urbanas, es decir, aproximadamente un sexto de la población rural, entre ella, en su mayoría, jóvenes de 15 a 19 años de edad.

A pesar de que han transcurrido más de dos décadas desde entonces, quienes hoy viven en el campo siguen careciendo de la posibilidad de acceder al sistema de educación escolar y, aún más, al de educación superior dada la ausencia de una infraestructura cercana a sus territorios. Obando (2016) identifica el origen de este círculo vicioso en la nula voluntad política de los Gobiernos de turno locales y nacionales, los cuales evaden su responsabilidad de resolver los problemas de desigualdad social y económica de la población rural, y, más bien, se orientan a paliar a corto plazo la situación de precariedad de esos sectores, entregando recursos que no alcanzan a transformar de forma permanente su realidad estructural.

¿Cuál es la raíz del problema? Aparte de las dificultades de acceso a la educación universitaria, los jóvenes optan, una vez obtenido su bachillerato, por no proseguir estudios superiores, pues estos no les representan ningún beneficio material; en su lugar, prefieren trabajar para recibir un incentivo tangible. Esta coyuntura se repite en otras zonas rurales de Latinoamérica; así lo muestra el caso de estudio de los jóvenes colombianos del municipio de Lebrija (Herrera y Rivera, 2020), cuya situación nos devuelve a la pregunta con la que se inició este párrafo.

En Ecuador y, específicamente, en la zona rural del cantón Santa Lucía, los jóvenes no desean cursar una carrera universitaria en razón de que, al final del camino, no vislumbran un futuro prometedor, amén de que los procedimientos de acceso al sistema educativo en ese nivel (cupos, exámenes de ingreso, instrumentos de evaluación como el examen Ser Bachiller) los desmotivan. El informe de los talleres previos al diagnóstico territorial del Plan de Desarrollo y Ordenamiento Territorial 2021-2032 (PDYOT), implementado por el GAD del Cantón Santa Lucía (2021), reveló que a los varones se los empuja a una temprana inserción laboral o que un posterior desempleo los lleva al consumo de drogas; en cuanto a las mujeres, su marginación de las actividades agrícolas y las pocas oportunidades laborales locales las obligan a migrar, bien para estudiar, bien para trabajar en quehaceres domésticos. El ya citado informe también subraya que, por falta de orientación sexual integral, estas se hallan proclives al embarazo adolescente.

Por otro lado, los datos sobre trabajo y empleo del cantón Daule registran que un 15.13 $\%$ de los jóvenes entre 15 y 17 años está inserto en la estructura agro-productiva; un fenómeno que provoca la deserción escolar a nivel de bachillerato e incide en la tendencia a que formen familia o empiecen a consumir drogas (GAD Cantón Daule, 2021).

Al igual que Gajardo (2014) y Corvalán (2006), el PDYOT (Plan de Desarrollo y Ordenamiento Territorial) del cantón Santa Lucía dio a conocer un caso, el de un colegio del recinto El Porvenir - recinto en el corazón de un área altamente arrocera-, donde se sustituyeron carreras del ámbito agrícola por las de la esfera informática. Tal es el motivo por 
el que los jóvenes recientemente egresados no ejercen lo aprendido: no existe una oferta laboral acorde con su nueva especialización. El escenario se agrava si se toma en consideración el aumento de una mano de obra no cualificada que busca emplearse como albañil, peón agrícola o en camaroneras, dependiente en comercios informales, conductor de mototaxi..., lo que genera problemáticas cantonales relacionadas con temas ambientales y de exceso y desorganización del transporte urbano y rural, que los GAD (Gobiernos Autónomos Descentralizados) deben contener y normalizar.

El propósito de este estudio fue explorar e identificar las situaciones que desde hace décadas confronta el entorno agrícola de Daule, Santa Lucía y Salitre e impiden que estos cantones alcancen un desarrollo rural sostenido que mejore y transforme la calidad de vida de los agricultores.

La presente investigación se desarrolló aplicando una metodología cualitativa basada en fuentes secundarias, las cuales complementaron los hallazgos de factores endógenos y exógenos que intervienen en la cotidianidad de Daule, Santa Lucía y Salitre. En una segunda exploración se buscó identificar políticas públicas que cambien dicho panorama; por ello, se recurrió al Plan Nacional del Buen Vivir 2017-2021, un instrumento clave de desarrollo estratégico.

Cada objetivo de este Plan Nacional se constituyó en un eje de análisis que permitió identificar la realidad social, política y económica de los antedichos cantones, y, por lo tanto, trabajar en la potenciación de cada uno de aquellos ejes. Además, como ya se señaló, la raíz de esta problemática se encuentra en la falta de preparación de los jóvenes rurales de resultados de la ausencia de una infraestructura universitaria agropecuaria dentro de sus territorios.

Este estudio parte de la convicción de que el acceso de los jóvenes a la educación de tercer nivel, junto con la implementación de las políticas públicas que constan en el Plan Nacional de Desarrollo (PND), atenuarán los problemas endógenos y exógenos de los tres cantones. Con el fin de medir el interés de los jóvenes sobre la propuesta de crear una universidad agropecuaria en la zona de Daule, Santa Lucía y Salitre, y ante la imposibilidad de obtener una muestra aleatoria a causa de que esta investigación se llevó a cabo durante el periodo de la pandemia, se trabajó con una muestra dirigida o no probabilística, denominada también "muestras por conveniencia", esto es, los casos disponibles a los cuales se tiene acceso (Battaglia, 2008a, citado por Hernández et al., 2014 y Roque et al., 2018). El cuestionario se aplicó entre el 18 de marzo y el 27 de abril de 2021 a una muestra constituida por jóvenes de entre los 16 y 24 años, residentes de los tres cantones en mención, a través de los formularios en línea de Google.

\section{Objetivo}

Proponer la creación de una universidad agropecuaria en la zona de Daule, Santa Lucía y Salitre con el fin de preparar académicamente a los jóvenes cerca de sus territorios y minimizar el impacto de los factores endógenos y exógenos en su entorno agrícola, implementando políticas públicas del Plan Nacional de Desarrollo 2017-2021, para, con ello, garantizar el desarrollo sostenible de ese sector de la provincia del Guayas.

¿Qué problemas han llevado a la necesidad de crear una universidad agropecuaria en la zona de Daule, Santa Lucía y Salitre? ¿Cuáles son los factores endógenos y exógenos que con frecuencia golpean el entorno agrícola de los tres cantones? ¿La implementación de políticas públicas impulsará la creación de un entorno económico, social y ambiental favorable en los tres cantones? 
"Es necesario acabar con la dicotomía urbano-rural" (CEPAL, FAO e IICA, 20192020). El mayor crecimiento de la población urbana de América Latina y el Caribe con respecto de la rural es lo que ha invisibilizado los espacios rurales en las políticas públicas y en las discusiones de acuerdos internacionales. Esa pérdida de visibilidad responde a una óptica exclusivamente demográfica que aparece alejada de una auténtica perspectiva territorial: "son espacios que coexisten y se impactan de forma recíproca en los esfuerzos por alcanzar las metas de la Agenda 2030"; es decir, abordar el desarrollo haciendo énfasis en las dimensiones económica, social y ambiental y proponiendo modelos que igualen el crecimiento económico y el desarrollo social e inclusivo tanto en lo rural como en lo urbano. Sin ese compromiso, será imposible alcanzar los objetivos Hambre Cero o Fin a la Pobreza, entre otros, de la Agenda de la Organización de las Naciones Unidas (ONU).

\section{Ubicación geográfica y potencial agrícola de la zona de estudio}

El Laurel es una parroquia rural del cantón Daule que se creó mediante el Registro Oficial N. 571 del 25 de noviembre de 1986. Está ubicada en la zona norte de la cabecera cantonal y tiene una población de 9882 habitantes, una superficie de $36,61 \mathrm{~km}^{2}$ y una densidad poblacional de 269,93 (INEC, 2010).

Posee 2 rutas de llegada: una a la altura del km 56 de la vía Guayaquil-Daule-Balzar y otra por la vía Guayaquil-Salitre La T-vía Los Quemados. Limita al norte con el cantón Santa Lucía, al sur con la parroquia Juan Bautista Aguirre del cantón Daule, al este con la parroquia Junquillal del cantón Salitre y al oeste con la parroquia Limonal del cantón Daule (GAD El Laurel, 2015).

Esta parroquia pertenece al cantón Daule y se caracteriza por ser una zona altamente comercial. Las aguas del río Pula, afluente del Vinces, divide El Laurel: en una ribera se asienta el recinto Laurel del cantón Salitre y en la opuesta, la parroquia El Laurel del cantón Daule. Activos comerciantes han ocupado, desde sus orígenes, ambas riberas. En un área adyacente, una entrada de agua procedente del Pula ha creado una zona denominada "Estero de El Salto", que corriente abajo limita con la parroquia Laurel de Daule y con el cantón Santa Lucía. Esta ubicación resulta estratégica y de alto potencial para desarrollar una universidad agropecuaria.

El Laurel constituye un punto de encuentro de habitantes propios y de tres cantones hermanos: Daule, Santa Lucía y Salitre, por cuanto es una tierra con un elevado componente agrícola, comercial, de intercambio y de navegabilidad.

\section{Daule, Santa Lucía y Salitre}

Los 3 cantones de la provincia del Guayas representan una extensión total de $1212 \mathrm{~km}^{2}$, y una población — urbana y rural-, proyectada por el INEC para el 2020, de 284453 habitantes (ver Figura 1).

El potencial actual y futuro de la producción agropecuaria de los tres cantones se corroboró consultando el documento Política Agropecuaria Ecuatoriana hacia el desarrollo territorial rural sostenible 2015-2025, del Ministerio de Agricultura, Ganadería, Acuacultura y Pesca (MAGAP, 2016), que consagra una sección a la ubicación geográfica de las zonas llamadas "Muy aptas para cultivos". El mapa de aptitud para esta categoría muestra que la provincia del Guayas se caracteriza por presentar relieves bajos a ligeramente ondulados y ondulados, con temperaturas superiores a los $21^{\circ} \mathrm{C}$; abarca tierras con pocas o ninguna limitación para el desarrollo de actividades agrícolas, pecuarias o forestales adaptadas ecológicamente a la zona. Es propicia para el cultivo de arroz, maíz duro, soya, uva, cacao, café, palma africana, yuca, algodón, guayaba, arazá, borojó, pitahaya, sandía, banano, 
chirimoya del litoral, limón, mango y maracuyá. El orden de aparición indica claramente que el arroz ocupa el primer lugar en toda la zona, mientras que el maíz duro, la soya, la yuca, la sandía y el mango son los cultivos predominantes en los 3 cantones, cuya producción es altamente arrocera, como se aprecia en la Tabla 1, en la cual se especifica el volumen de producción por tamaño de unidades de producción agrícolas (UPA).

\section{Figura 1}

Ubicación geográfica de Daule, Santa Lucía y Salitre

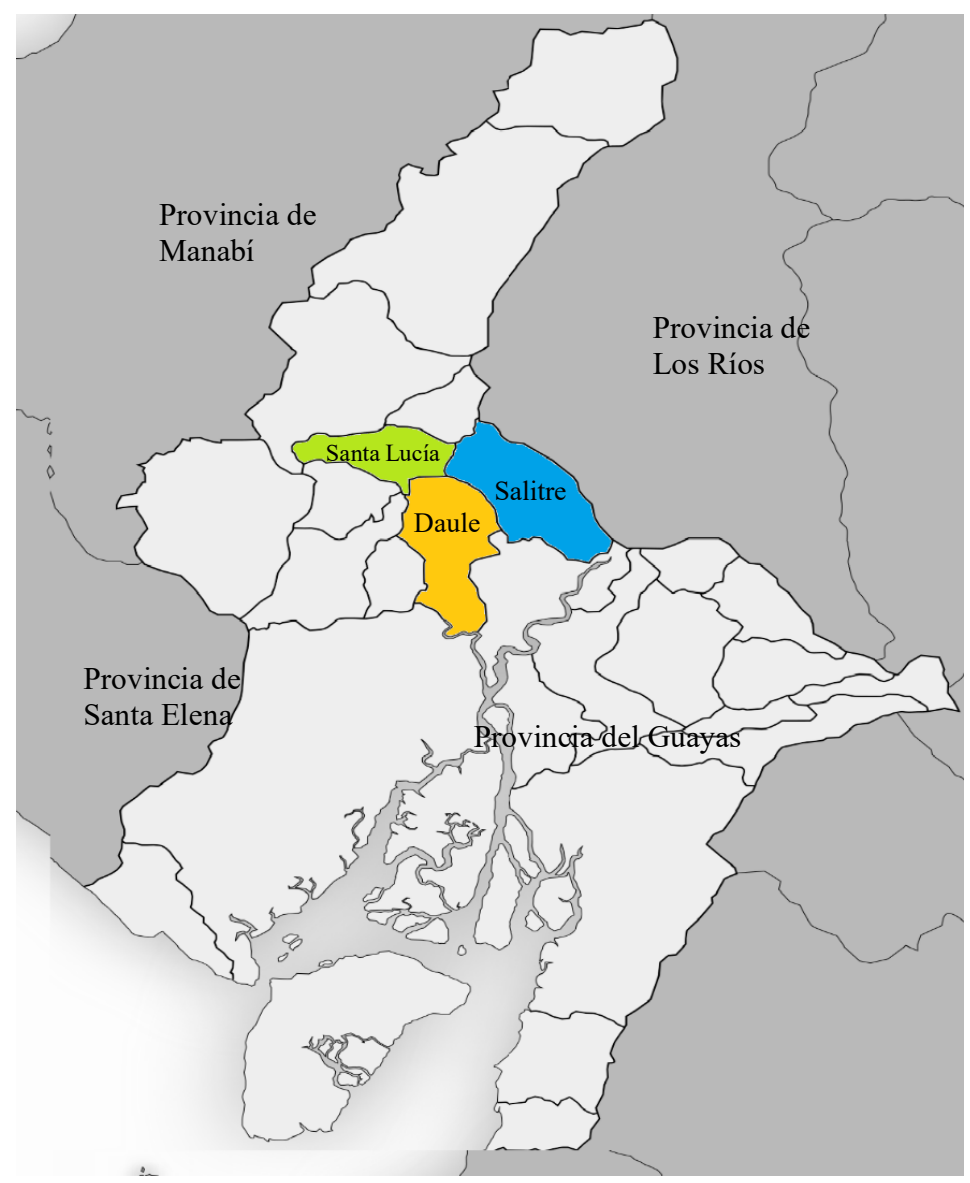

Tabla 1

Volumen de Producción por Tamaño de Unidad de Producción

\begin{tabular}{lcccc}
\hline & Menor a 5 ha & $\begin{array}{l}\text { De } 5 \text { ha a menor } \\
\text { de } 10 \text { ha }\end{array}$ & $\begin{array}{l}\text { De } 10 \text { ha a } \\
\text { menor de } 50 \text { ha }\end{array}$ & $\begin{array}{l}\text { Mayor a 50 } \\
\text { ha }\end{array}$ \\
$\begin{array}{l}\text { ARROZ (EN } \\
\text { CÁSCARA) }\end{array}$ & 183.357 & 149.088 & 345.363 & 421.878 \\
\hline
\end{tabular}

Nota. Tomado de la Encuesta de Superficie y Producción Agropecuaria Continua (ESPAC, 2019).

Al cantón Daule también se lo conoce como la "Capital Arrocera del Ecuador". El Ministerio de Agricultura, Ganadería, Acuacultura y Pesca (MAGAP), mediante el Acuerdo N. ${ }^{\circ} 36$, del 8 de agosto del 2013, ratificó la antedicha denominación. Cuenta con una población, proyectada por el INEC para el 2020, de 173684 habitantes y una superficie de $462 \mathrm{~km}^{2}$, según datos del Censo 2010 de Población y Vivienda (INEC, 2010). Limita al norte con el cantón Santa Lucía, al sur con Guayaquil, al este con Salitre y Samborondón y al oeste con Nobol y 
Lomas de Sargentillo. Sus pobladores proceden de las tribus de los Daulis. Antes y después de la conquista, Daule ha estado habitada por hombres y mujeres de valor e inteligencia que han contribuido a la prosperidad agrícola del país, como consta en los apuntes de Caicedo (1902). Francisco de Paula Santander, vicepresidente de la Gran Colombia y encargado del Poder Ejecutivo, firmó el 10 de febrero del 1826, en el Palacio de Gobierno de Bogotá, el decreto que lo erigía en Villa. Según Caicedo (1902), era uno de los cantones más extensos del país y estaba formado por las siguientes parroquias: Santa Lucía, Colimes, Balzar, De las Ramas, Soledad, Pedro Carbo y Piedrahita, las cuales, en vista de su crecimiento poblacional y desarrollo, adquirieron la categoría de cantones. El actual Daule se divide en 4 parroquias rurales: Juan Bautista Aguirre, Limonal, Los Lojas y El Laurel.

Santa Lucía es el segundo cantón arrocero del Guayas. Sus 18000 hectáreas de ese cultivo constituyen la principal actividad de una población que vive en más de 114 recintos (E1 Comercio, 2019). Cuenta con una población, proyectada por el INEC para el 2020, de 45004 habitantes y una superficie de 357,86 km², según datos del Censo 2010 de Población y Vivienda (INEC, 2010). Limita al norte con los cantones Colimes y Palestina, al sur con los cantones Daule, Isidro Ayora y Lomas de Sargentillo, al este con el cantón Salitre y al oeste con el cantón Pedro Carbo. La población desciende de una aguerrida etnia, los chonanis, que vivían de la cacería, la pesca, la agricultura y del intercambio comercial. Este cantón carece de parroquias rurales.

Salitre, cantón ubicado a poco más de $40 \mathrm{~km}$ de Guayaquil, fue declarado, mediante ordenanza de octubre de 2000, "Capital Montubia del Ecuador". Los montubios son gente sencilla con mística de trabajo, que vive de lo que le da la tierra y el río y que adhiere a valores como la lealtad, la amabilidad, la generosidad y el honor (El Universo, 2002).

Esta zona nació como parroquia Las Ramas, aunque, por ser una tierra salitrosa, se la llamaba "El Salitre". Luego, en el momento de su cantonización, el 27 de noviembre de 1959, recibió el nombre de Urbina Jado en memoria de Francisco Urbina Jado, gerente del Banco Comercial y Agrícola de Guayaquil, entidad creada en 1894 que gozaba de la facultad de emitir dinero, razón por la cual en poco tiempo se convirtió en la base económica de la exportación, la industria y el comercio del puerto principal (El Telégrafo, 2014). Posteriormente, en 1998 el cantón retomó el nombre de Salitre, denominación más común entre sus habitantes.

El cantón Salitre formaba parte de los dominios de la cultura Milagro-Quevedo, lo que se evidencia por la cantidad de 'lomas' o 'tolas' localizadas. En esos asentamientos se han encontrado tanto objetos decorativos personales u ornamentales de plata o cobre mezclado con oro como vasijas de barro. Las tolas son una muestra tangible del pasado (El Telégrafo, 2017).

Cuenta con una población, proyectada por el INEC para el 2020, de 65765 habitantes y una superficie de $393 \mathrm{~km}^{2}$, según datos del Censo 2010 de Población y Vivienda (INEC, 2010). Limita al norte y al este con la provincia de Los Ríos, al sur con el cantón Samborondón y al oeste con Daule, Santa Lucía y Palestina. Posee 3 parroquias rurales: General Vernaza, Junquillal y La Victoria, y 1 urbana: Salitre (Las Ramas).

\section{Marco legal}

El Art. 26 de la Constitución de la República del Ecuador establece:

La educación es un derecho de las personas a lo largo de su vida y un deber ineludible e inexcusable del Estado. Constituye un área prioritaria de la política pública y de la inversión estatal, garantía de la igualdad e inclusión social y condición indispensable 
para el buen vivir. Las personas, las familias y la sociedad tienen el derecho y la responsabilidad de participar en el proceso educativo. (Constitución del Ecuador, 2008, p. 32)

La Ley Orgánica de Educación Superior, ente regulador del sistema de educación superior en el Ecuador, en su artículo 4 señala que:

Derecho a la Educación Superior. - El derecho a la educación superior consiste en el ejercicio efectivo de la igualdad de oportunidades, en función de los méritos respectivos, a fin de acceder a una formación académica y profesional con producción de conocimiento pertinente y de excelencia. Los ciudadanos y las ciudadanas en forma individual y colectiva, las comunidades, pueblos y nacionalidades tienen el derecho y la responsabilidad de participar en el proceso educativo superior, a través de los mecanismos establecidos en la Constitución y esta Ley. (LOES, 2010, p. 7)

¿Qué debe hacer el Estado? El Consejo Nacional de Planificación 2017-2021, a través de la Secretaría Nacional de Planificación (SENPLADES), lleva a cabo planes y programas para el país. Cabe anotar que, para crear una universidad en el Ecuador, se requiere un informe previo favorable y obligatorio del organismo nacional de planificación (LOES, Cap. 2, artículo 108):

Art. 108.- Creación de universidades y escuelas politécnicas. - Las universidades y escuelas politécnicas públicas y particulares se crearán por Ley, previo informe favorable vinculante del Consejo de Educación Superior a la Asamblea Nacional.

El informe del Consejo de Educación Superior tendrá como base el informe previo favorable y obligatorio del organismo nacional de planificación quien lo presentará en un plazo máximo de 100 días.

Una vez se cuente con el informe anterior el Consejo de Educación Superior requerirá el informe previo favorable y obligatorio del Consejo de Evaluación, Acreditación y Aseguramiento de la Calidad de la Educación Superior que tendrá un plazo máximo de 100 días para presentarlo. (LOES, 2010, p. 43)

El documento Politica Agropecuaria Ecuatoriana hacia el desarrollo territorial rural sostenible 2015-2025, elaborado por el Ministerio de Agricultura, Ganadería, Acuacultura y Pesca (MAGAP, 2016), hace un diagnóstico de la situación: insuficiente investigación, desarrollo tecnológico e innovación en el sector agrícola; $\mathrm{y}$, a la vez, presenta una propuesta de fortalecimiento para afrontar esa debilidad $\mathrm{y}$, en articulación con otras instancias del ejecutivo, entre ellas la SENESCYT, identificar institutos tecnológicos que permitan impulsar las carreras o los perfiles relacionados con las actividades agropecuarias en el territorio.

Sobre esta misma línea, cabe resaltar que, en enero de 2021, se firmó el convenio "Proyecto Colegios Agropecuarios Sostenibles, pasión que se siembra" entre el Ministerio de Agricultura y Ganadería (MAG) y el Ministerio de Educación, el cual involucra docentes y estudiantes de las unidades educativas de bachillerato, quienes contarán con la asesoría y tecnología del MAG para la venta de la producción que se genere en las unidades educativas; un modelo piloto en el que participará el Galo Plaza Lasso de Daule. 


\section{Desarrollo}

Tanto factores internos como externos, pasados como actuales, han sido y siguen siendo la constante en la cotidianidad rural y urbana de los tres cantones. Si bien es cierto que se han producido mejoras a través de los años: uso de semillas certificadas, investigaciones que han ayudado a prevenir y controlar plagas y enfermedades, inversiones en mecanización de procesos..., generaciones de agricultores que se han servido, a lo largo de su vida, de conocimientos ancestrales - aunque a veces hayan recibido la asesoría de organismos técnicos, como el MAG - se enfrentan hoy a nuevas realidades sociales, políticas, económicas, ambientales, sanitarias, tecnológicas..., muchas veces incomprensibles por desconocimiento o falta de preparación académica. Estamos ante un fenómeno que, en las zonas rurales, está pasando y pasará una factura muy alta a las actuales y siguientes generaciones si no se combate el problema de raíz.

En esta investigación se describen los factores endógenos, es decir, aquellos que son propios u originarios de Daule, Santa Lucía y Salitre y que los ciudadanos y las autoridades locales pueden controlar, y los factores exógenos, esto es, aquellos cuya influencia u origen son externos. Se trata de situaciones que los agricultores no controlan, bien por desprotección, bien por desarticulación entre el Estado y sus organismos dependientes.

\section{Tabla 2}

Factores endógenos y exógenos de los tres cantones

\begin{tabular}{|c|c|}
\hline Factores exógenos & Factores endógenos \\
\hline \multirow{2}{*}{$\begin{array}{l}\text { 1. Los efectos del cambio climático. } \\
\text { Riesgos de inundaciones. }\end{array}$} & 1. Limitada formación académica. \\
\hline & $\begin{array}{l}\text { 2. Estructura educativa sin pertinencia con la } \\
\text { estructura productiva de los tres cantones. }\end{array}$ \\
\hline 2. Escaso crédito bancario a agricultores. & 3. Jóvenes sin proyecto vida. \\
\hline $\begin{array}{l}\text { 3. No regularización de la posesión de } \\
\text { los predios. }\end{array}$ & $\begin{array}{l}\text { 4. Baja valoración, por parte de padres, de las } \\
\text { potencialidades de los niños. }\end{array}$ \\
\hline 4. Desempleo en las zonas rurales. & $\begin{array}{l}\text { 5. Falta de conocimientos especializados en toda la } \\
\text { cadena de valor para productos de la zona }\end{array}$ \\
\hline \multirow[t]{5}{*}{ 5. Migración campo-ciudad. } & $\begin{array}{l}\text { 6. Dificultades de financiamiento y movilización a } \\
\text { centros de estudios especializados. }\end{array}$ \\
\hline & 7. Falta de una verdadera vida asociativa. \\
\hline & $\begin{array}{l}\text { 8. Falta de capacidad de reacción de los } \\
\text { agricultores frente al gobierno e intermediarios }\end{array}$ \\
\hline & $\begin{array}{l}\text { 9. Servicio formal de transporte terrestre formal no } \\
\text { llega a los alrededores ni caseríos. }\end{array}$ \\
\hline & $\begin{array}{l}\text { 10. Mal estado, en un } 90 \% \text {, de las vías de tercer, } \\
\text { cuarto y quinto orden en Santa Lucía y Salitre. }\end{array}$ \\
\hline
\end{tabular}

Nota. Recopilación por observación directa y de PDYOT (GAD Cantón Daule, 2021; GAD Cantón Salitre, 2020; GAD Cantón Santa Lucía, 2021)

El Plan Nacional de Desarrollo (PND) 2017-2021 dispone que las distintas funciones del Estado, los niveles de gobierno, la sociedad y los diversos actores económicos saquen adelante las labores de coordinación, información y definición de estrategias para la adecuada implementación y ejecución de políticas públicas integrales en áreas fundamentales. 
Dado que esta es una investigación enfocada en un área clave como es la de la educación para un sector estratégico rural —en este caso, los cantones de Daule, Santa Lucía y Salitre, con un fuerte bagaje histórico, geográfico, social y económico-, urge la puesta en marcha de las mencionadas políticas públicas integrales a fin de contrarrestar los factores exógenos y endógenos que operan en el contexto de dichos territorios.

\section{Detalles de las Políticas Objetivo del PND versus los factores exógenos o endógenos \\ FACTOR ENDÓGENO}

Limitada formación académica de los agricultores y falta de visión para cumplir los Objetivos de Desarrollo Sostenible (ODS) hasta el 2030.

Estructura educativa sin pertinencia con la estructura productiva de los tres cantones. Jóvenes sin proyecto de vida, una vez culminado el ciclo educativo.

Baja valoración, por parte de los padres, de las potencialidades de los niños, niñas y jóvenes, especialmente en el sector rural (GAD Cantón Santa Lucía, 2021).

\section{Política Objetivo 1}

1.6 Garantizar el derecho a la salud, la educación y al cuidado integral durante el ciclo de vida, bajo criterios de accesibilidad, calidad y pertinencia territorial y cultural.

La limitada formación académica de los agricultores y su falta de visión para cumplir los Objetivos de Desarrollo Sostenible (ODS) hasta el 2030 constituye uno de los principales factores endógenos predisponentes de la problemática agrícola que afecta los tres cantones (GAD Cantón Santa Lucía, 2021). El estudio Juventud rural y empleo decente en América Latina (FAO, 2016) establece una clara correlación entre niveles de educación y tipo de unidad agropecuaria. Los agricultores con más bajos niveles de educación tienen menores capacidades de gerencia, razón por la cual tienen mayores dificultades para transitar de la agricultura de subsistencia a la agricultura comercial.

Es un derecho recibir educación superior bajo criterios de accesibilidad dentro del propio territorio. El documento PDYOT muestra su preocupación a propósito de que la estructura educativa no posea pertinencia con respecto de la estructura productiva (GAD Cantón Santa Lucía, 2021). Así sucede porque se ha intentado "universalizar" la educación a través de la imposición de los mismos textos, currículos y metodologías, olvidando que su impacto varía según el contexto (urbano o rural), los factores familiares, socioeconómicos y psicoemocionales. Aunque se hayan logrado avances en el sistema educativo, especialmente en los niveles básicos de las áreas rurales, Contreras (2015) hace hincapié en que todavía no se ha trabajado en la problemática específica y estructural que persiste en las zonas rurales, lo que ocasiona su despoblamiento y una desvinculación de las tradiciones productivas de los jóvenes con sus territorios, ya que, una vez que estos emigran a zonas urbanas, difícilmente regresan al campo.

Asimismo, resulta preocupante la baja valoración, por parte de los padres, de las potencialidades de niños y jóvenes (GAD Cantón Santa Lucía, 2021); esto obedece a la igualmente baja percepción de la rentabilidad futura de las oportunidades en las zonas rurales (Contreras, 2015). El acceso a la educación y salud como derechos, indirectamente implica conferir al habitante rural un papel protagónico para que levante las zonas agrícolas, las preserve y garantice la seguridad y soberanía alimentaria. 


\section{FACTOR EXÓGENO}

Los efectos del cambio climático (GAD Cantón Santa Lucía, 2021).

Las zonas de Salitre y Santa Lucía, localizadas en la llanura de inundación de la cuenca baja del río Guayas, pueden sufrir riesgos de inundaciones al igual que Daule en la época lluviosa.
Política Objetivo 3

Al Gobierno, a través del MAG, le queda aún mucha tarea pendiente para dar paso a la agricultura orgánica, reducir o reemplazar los fertilizantes por abonos naturales — caso del arroz y demás productos de la zona- De acuerdo con la bibliografía revisada sobre los tres cantones, los GAD subrayan que, en la medida en que los agricultores están conscientes de que el cambio climático es una amenaza actual y futura, urge la sensibilización para el uso de energías limpias y la minimización del empleo de insumos químicos (GAD Cantón Santa Lucía, 2021).

Iniciativas como la del pago por servicios ambientales a los agricultores se han desarrollado en algunos países, entre ellos Costa Rica. Los agricultores que buscan la sostenibilidad del ecosistema (proteger las márgenes de los ríos, preservar los hábitats naturales, enriquecer suelo) reciben una compensación no solo por las cosechas estacionales que producen y venden, sino también por los servicios ambientales públicos que su establecimiento o parcela agrícola proporciona durante todo el año. Con ello se busca atenuar las oscilaciones de los ingresos del agricultor en tiempos de volatilidad de los precios de mercados, lo que hoy en día se ha vuelto muy usual en nuestra zona (Nieuwkoop, 2019).

Otro factor exógeno son las inundaciones, las cuales destruyen gran parte de los cultivos y provocan graves pérdidas económicas en los agro-productores, especialmente en los pequeños, financiados con créditos. Con vistas a mitigar los efectos del cambio climático y adaptarse a ellos, se torna prioritaria la consolidación de estructuras institucionales permanentes y sostenibles (Gobierno central, GAD, pobladores...), que, por medio de la planificación, la inversión, las prácticas y las políticas sectoriales, manejen ese riesgo y otros latentes en el área de los tres cantones; riesgos que van más allá de la pérdida momentánea de ingresos y oportunidades, toda vez que se trata de un problema de seguridad alimentaria y supervivencia (Lavell y Witkowski, 2016).

\section{Política Objetivo 4}

\section{FACTOR EXÓGENO}

Escaso crédito de la banca privada a agricultores. Banca pública con alta burocracia, mal canalizada y extemporánea.
4.3 Promover el acceso de la población al crédito y a los servicios del sistema financiero nacional, $y$ fomentar la inclusión financiera en un marco de desarrollo sostenible, solidario y con equidad territorial.

Esta política objetivo marca un giro decisivo en beneficio de los agricultores de las poblaciones excluidas; sin embargo, la realidad es otra. La bibliografía revisada muestra que, si bien existen entidades bancarias, cooperativas de ahorro y crédito y mutualistas, sus servicios resultan limitados en comparación con los ofrecidos por los chulqueros o prestamistas informales. 
En Santa Lucía, tanto la banca pública como la privada se perciben como escasas y mal direccionadas. Acceder a un crédito entraña trámites burocráticos interminables y requisitos inalcanzables de cumplir (GAD Cantón Santa Lucía, 2021); una situación que empuja a realizar préstamos informales con altas tasas de interés a los chulqueros, a los proveedores de bienes (semillas, insumos) o servicios (piladoras) o a los propios intermediarios, convirtiéndose así la negociación en ventas anticipadas de la cosecha, lo que forja una cultura cíclica de préstamoendeudamiento que afecta económica y moralmente al pequeño y mediano productor (Burgos Guerrero et al., 2011).

El Gobierno de Costa Rica ha diseñado programas y herramientas que han incentivado la inclusión financiera. Los fondos provenientes de las ayudas sociales se transfieren a la cuenta de ahorro, que, como parte de los requisitos, se ha exigido abrir al beneficiario. Esto sumado a la presencia de la banca estatal, con 531 sucursales y más de 1400 cajeros automáticos ubicados en todas las regiones del país, además de servicios complementarios: microseguros, acompañamiento técnico, educación financiera $\mathrm{y}$ acceso a las TIC, ha contribuido enormemente a la ya referida inclusión financiera. Aquella estrategia ha posibilitado llegar a la base de la pirámide y potenciar la migración de los productores rurales hacia sistemas formales más productivos y de menor riesgo (Villarreal, 2017).

\section{FACTOR ENDÓGENO}

Escasez en cuanto preparación técnica de los agricultores; estructura educativa sin pertinencia con la estructura productiva

Inversión pública y privada, interna o externa en actividades productivas del cantón (GAD Cantón Santa Lucía, 2021).
Política Objetivo 4

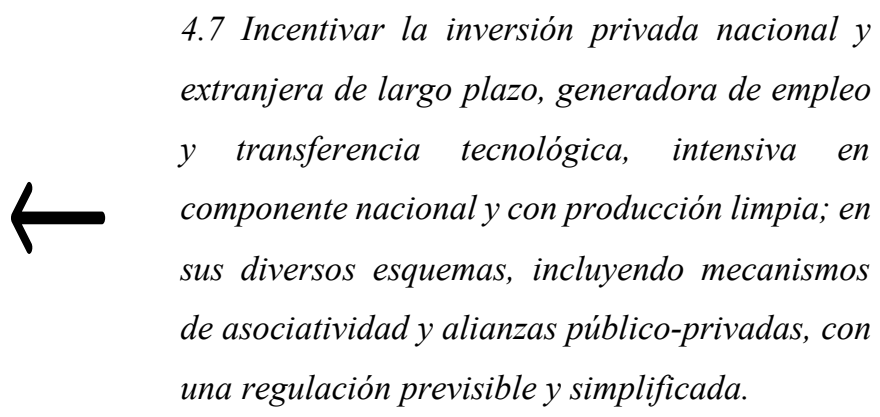

4.7 Incentivar la inversión privada nacional y extranjera de largo plazo, generadora de empleo y transferencia tecnológica, intensiva en componente nacional y con producción limpia; en sus diversos esquemas, incluyendo mecanismos una regulación previsible y simplificada.

Una manera de impulsar esta política objetivo en los tres cantones es bajo la modalidad "redes alternativas de alimentos", que activaría la conexión productor-consumidor y la vinculación de los alimentos a territorios y culturas, al recuperar aspectos como arraigo, identidad social, calidad y manejo de las prácticas amigables con el ambiente (Renting et al., 2003; Feagan, 2007; Bowen, 2011, citados por Rodríguez-González et al., 2015).

El estudio Cuatro maneras de combatir la pobreza con la agricultura (Banco Mundial, 2016), por su parte, describe la experiencia de tres décadas de alianza entre el Gobierno de Brasil y el Banco Mundial, la cual ha posibilitado brindar formación teórica y actividades prácticas en el campo e información confiable a un público (campesinos) que no siempre tiene acceso a la educación formal, la televisión o el internet. Dicha experiencia podría reproducirse en Daule, Santa Lucía y Salitre, con productores de arroz, maíz, soya, cacao, tabaco, mango, sandía, melón, maracuyá, vegetales, yuca, verde, tomates, frejol tierno, pimientos...

Siendo la agricultura la principal actividad económica de los tres cantones, estos, unidos o en alianza, podrían proponer iniciativas al Gobierno central para así empezar a encaminar la llegada de inversiones a la zona. En el caso del arroz, por ejemplo, hay poco aprovechamiento de sus subproductos: el polvillo, el arrocillo y la cáscara (GAD Cantón Santa Lucía, 2021). 
El perfil de egreso de los profesionales de la Universidad Agropecuaria devendrá estratégico para la industria de derivados y transformación de alimentos, a saber: bebidas y mermeladas de frutas tropicales, harina de arroz, bebidas de arroz, productos de limpieza a base de desechos de arroz, elaborados de soya, artículos de cuero..., lo que redundará en provecho de otros habitantes del sector, ya que aquellas actividades industriales se traducen en el empleo de mano de obra local y el impulso de actividades no agrícolas (alimentación, hospedaje, transporte).

Sumberg y Sabates-Wheeler (2010, 2011) y Rodríguez-González et al. (2015) coinciden en destacar que un planteamiento tal produce grandes beneficios a los productores $\mathrm{y}$, de forma general, a la comunidad y a los actores que participan en las cadenas alimenticias por la dinámica de bienes y servicios disponibles, contribuyendo de esa manera al desarrollo.

\section{FACTOR ENDÓGENO}

Falta de conocimientos especializados (GAD Cantón Santa Lucía, 2021).

Dificultades de financiamiento y movilización a centros de estudios especializados (GAD Cantón Santa Lucía, 2021).

\section{Política Objetivo 5}

5.6 Promover la investigación, la formación, la capacitación, el desarrollo y la transferencia tecnológica, la innovación y el emprendimiento, la protección de la propiedad intelectual, para impulsar el cambio de la matriz productiva mediante la vinculación entre el sector público, productivo y las universidades.,

No existe una estimación precisa de los recursos de $\mathrm{I}+\mathrm{D}+\mathrm{i}$ para el sector agropecuario y forestal del Ecuador (invertidos por otros organismos públicos y el sector privado), pero difícilmente superan el $0,15 \%$ del PIB, con lo cual la asignación total de recursos para $\mathrm{I}+\mathrm{D}+\mathrm{i}$

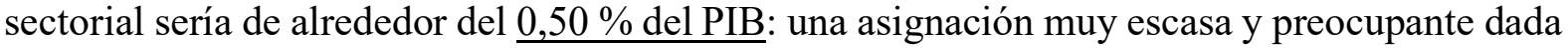
la importancia actual y el potencial del sector agropecuario y forestal de este país (MAGAP, 2016).

Los resultados de la investigación e innovación tecnológica deben aplicarse a las necesidades agropecuarias y estimular las actividades agrícolas, pecuarias o forestales. A la innovación y transferencia de conocimientos, se suman los conocimientos ancestrales de los productores como fuentes de mejoramiento para diversificar las actuales formas de producción y activar la producción campesina.

Esta política objetivo conecta empresa privada, Estado y universidades entre sí con el fin de estimular la productividad y competitividad. La universidad, además de sus misiones básicas de enseñanza e investigación, tiene una tercera: la generación, el uso, la aplicación y la explotación del conocimiento; para ello, requiere volverse parte de un sistema que incluye a las empresas y al gobierno, formando la "triple hélice", que apuntala la innovación y el desarrollo económico (Sarabia-Altamirano, 2016). Esto atenuará los efectos del factor endógeno relacionado con las actividades productivas rurales poco tecnificadas (GAD Cantón Santa Lucía, 2021).

La "triple hélice" fusionará conocimientos con miras a formar especialistas en almacenamiento, comercialización, distribución, transporte, logística, empaque, control de calidad y toda la cadena de valor para productos de la zona: una de las demandas laborales no explotadas en ese sector que permitirá levantar zonas agrícolas deprimidas favoreciendo la 
producción y la mano de obra local; y, de ser el caso, trasladando la mano de obra de la ciudad al campo (Dinámica de M.O. + salarios $=+$ ingresos familias) (GAD Cantón Santa Lucía, 2021).

\section{FACTOR EXÓGENO}

Desempleo en las zonas rurales por mano de obra no cualificada, especialmente de jóvenes varones; y desigualdad de género en el caso de las mujeres (GAD Cantón Daule, 2021).

Falta de trabajo formal establecido en Salitre, lo cual está directamente relacionado con los picos de producción (GAD Cantón Salitre,

Política Objetivo 6 2020).
6.1 Fomentar el trabajo y el empleo digno con énfasis en zonas rurales, potenciando las capacidades productivas, combatiendo la precarización y fortaleciendo el apoyo focalizado del Estado e impulsando el emprendimiento.

El desempleo, factor exógeno en los tres cantones, desencadena problemas como consumo de drogas u oferta de mano de obra no cualificada en actividades no formales. En la zona rural de Daule, a los varones se los hace participar a temprana edad en actividades agrícolas, factor causante de la deserción escolar, y a las mujeres se las excluye de las actividades agro-productivas, relegándolas a lo doméstico: situación que las lleva a migrar a los centros urbanos (GAD Cantón Daule, 2021). En el caso de Salitre, no existe un trabajo formal establecido, lo cual está directamente relacionado con los picos de producción (GAD Cantón Salitre, 2020).

Apremia que los GAD y el Gobierno central se focalicen en la realidad social de los pueblos; de no hacerlo nos pondríamos en una posición contraria a lo que la comunidad mundial se ha comprometido con el objetivo 2 de los Objetivos de Desarrollo Sostenible (ODS): terminar con todas las formas de hambre y desnutrición hasta el 2030. Esta tarea conlleva poner a las mujeres en un rol protagónico, pues ellas, al tener un mejor acceso a la información, la capacitación y las tecnologías, pueden convertirse en agentes de cambio fundamentales en los ámbitos de la agricultura, la nutrición y el desarrollo rural (Banco Mundial, 2017).

\section{FACTOR EXÓGENO}

Alto porcentaje de la población urbana y rural no tiene regularizada la posesión de los predios (GAD Cantón Santa Lucía, 2021).

Fundar universidades en el campo. Habilitación de tierras para actividades académicas de educación superior teóricas y prácticas.

\section{Política Objetivo 6}

6.2 Promover la redistribución de tierras y el acceso equitativo a los medios de producción, con énfasis en agua y semillas, así como el desarrollo de infraestructura necesaria para incrementar la productividad, el comercio, la competitividad y la calidad de la producción rural, considerando las ventajas competitivas y comparativas territoriales.

El análisis del potencial productivo de la provincia del Guayas mostró que las condiciones naturales de sus suelos, su topografía y clima la convertían en una zona agrícola de primera, particularmente en los cantones de El Empalme, Colimes y ciertas zonas de Balzar, 
así como al este de la provincia, en los cantones de Santa Lucía, Salitre, Daule, Samborondón, Alfredo Baquerizo Moreno, Simón Bolívar, Yaguachi, Naranjito, Durán, Nobol y Guayaquil (MAGAP, 2016).

Sin embargo, uno de los factores exógenos negativos es la no regularización de la posesión de sus predios; una realidad que se opone a la política objetivo de entregar seguridad jurídica sobre la propiedad a campesinos y agricultores para su mayor bienestar y permanencia y para la sostenibilidad agrícola de sus territorios y los de la región. Vivir en territorios rurales significa contar con la tierra como principal activo; en especial, las familias rurales: mujeres y hombres que viven en situación de pobreza, y cuyo bienestar humano y medios de subsistencia sostenibles dependen totalmente de la salud y la productividad de la tierra y guardan con ellas una estrecha relación (PNUD, 2016).

La Universidad del Azuay, en un estudio sobre la regularización predial en el Ecuador, asevera que los programas de titulación son la premisa para el desarrollo de las economías agrarias campesinas y que los inconvenientes que atávicamente estancan a la agricultura tradicional radican en la inseguridad en la tenencia de la tierra, la dificultad de acceso a créditos, la inadecuada tecnificación, la dificultad de acceso a mercados y la baja rentabilidad (Ochoa Arias y Enríquez García, 2017).

Dada la estrecha relación entre el ser humano y la tierra, el Estado debe garantizar, con el apoyo del Ministerio de Agricultura, Ganadería, Acuacultura y Pesca (MAGAP), a través de la Subsecretaría de Tierras Rurales y Territorios Ancestrales, los Gobiernos Autónomos Descentralizados (GAD), los Registros de la Propiedad y las Notarías, la entrega de títulos de propiedad a posesionarios de predios rurales mediante el actual Proyecto de Acceso a Tierras de los Productores Familiares y Legalización Masiva en el Territorio Ecuatoriano.

\section{FACTOR ENDÓGENO}

Una verdadera asociatividad.

Falta de capacidad de reacción ante temas sensibles inherentes a los productos de la zona - arroz(GAD Cantón Santa Lucía, 2021).

\section{Política Objetivo 6}

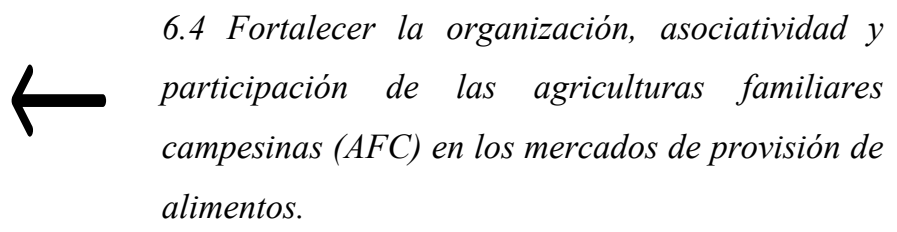

Los datos de la ESPAC para el año 2013 indican que, en el segmento de la pequeña agricultura campesina —o Agriculturas Familiares Campesinas (AFC) — predominan las unidades pequeñas; el $83 \%$ de estas son predios de menos de 20 hectáreas, su tamaño promedio es de 3,9 ha, controlan el $23 \%$ de la superficie productiva nacional y agrupan a casi 700 mil familias productoras. Este segmento es el proveedor de los alimentos de la dieta básica de los ecuatorianos y de rubros principales de exportación; por ello, su contribución al desarrollo territorial rural y al crecimiento económico del país resulta significativo (MAGAP, 2016).

El MAGAP, en sus políticas agropecuarias, afirma que solo se logrará una auténtica asociatividad entre los productores si esta deriva de la propia dinámica campesina, es decir, si se incentivan mecanismos generadores de confianza, relaciones de solidaridad y apoyo mutuo, valores que existen o surgen espontáneamente en las comunidades rurales. Los productores de hasta 20 ha encontrarían en ella un mecanismo de defensa.

Ante ese contexto, la política objetivo de asociatividad y participación permitiría a los agricultores a negociar en grupo o en bloque, vender producción, comprar insumos, solicitar 
créditos oportunos, buscar semilla certificada, tener facilidades de infraestructura de almacenamiento..., en fin, poseer todo lo necesario para minimizar los costos de producción. Asimismo, les conferiría una capacidad de liderazgo que los fortalecería frente las cadenas productivas e instancias del gobierno, bien para manejar incidentes, como el descontrol de precios, bien para presentar denuncias por ingreso de gramíneas procedentes de países vecinos: una problemática que demanda líderes comprometidos y preparados.

El desarrollo de las habilidades llamadas "blandas" les facilitará a los productores laborar en equipo, liderar, negociar, consensuar, sintetizar propuestas, trabajar bajo presión y en situaciones adversas. Por tal motivo, se torna prioritario y apremiante la planificación de esas habilidades en un currículo de estudio de quienes se formen en la universidad Agropecuaria.

\section{FACTOR ENDÓGENO}

Servicio formal de transporte terrestre solo llega a centros poblados (GAD Cantón Santa Lucía, 2021).

Mal estado, en un $90 \%$, de las vías de tercer, cuarto y quinto orden en Santa Lucía y Salitre.

\section{Política Objetivo 6}

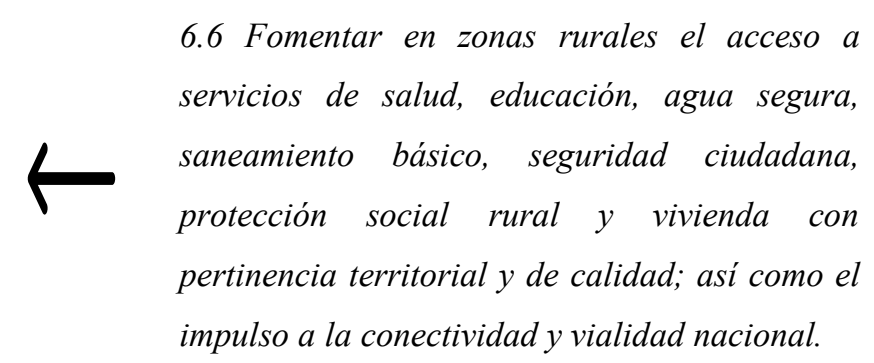

Un factor endógeno de esas zonas rurales son las vías de tercer, cuarto y quinto orden, puesto que alrededor del $90 \%$ se encuentran en mal estado. He aquí el porqué de que los recintos y poblaciones se aneguen durante la época invernal; esto obliga a que se saque la producción en canoas, carretones, lomo de caballos y acémilas, lo cual incrementa los costos de producción del pequeño y mediano productor. Adicionalmente, el servicio formal de transporte terrestre solo llega a centros poblados, segregando así a los habitantes de los alrededores o de caseríos, quienes deben salir a pie, bicicleta, caballo o moto. Estas últimas cobran entre 1 y 5 dólares por carrera (GAD Cantón Santa Lucía, 2021).

Dotar a los tres cantones de todos los servicios básicos deviene imperativo si se quiere poner en marcha un proyecto de educación superior, como el de la Universidad Agropecuaria. El Código Orgánico de Organización Territorial (COOTAD, 2011), en su Art. 55, faculta a los GAD municipales a trabajar de manera articulada con los organismos pertinentes de planificación nacional, regional, provincial y parroquial para regular el uso y la ocupación del suelo urbano y rural.

Entre las obras públicas más destacadas de los últimos gobiernos municipales de Daule, tenemos las viales, tanto en el sector urbano como en el rural, y las de alcantarillado; la pavimentación de calles; la dotación de agua potable y sus respectivas plantas de tratamiento en sectores rurales; los servicio de recolección de desechos; todo esto muy por encima de lo realizado en Santa Lucía y Salitre, cuyo alcalde identificó los desafíos y prioridades hasta el 2023: infraestructura sanitaria, salud, educación y vialidad; aparte de que se iniciaron diálogos con entidades del Gobierno para la ejecución de proyectos (El Comercio, 2019).

Esta política objetivo busca que el sector agrícola se abra a la cultura digital mediante la denominada "Agricultura digital", que consiste en disponer de una gran cantidad de datos que posibilita la optimización y racionalización de decisiones, el uso de recursos, los análisis predictivos y la anticipación de escenarios. Merced al uso de la tecnología se rompe el 
aislamiento tradicional de los agricultores, propiciando el intercambio peer to peer, que brinda la posibilidad de interacción entre los actores de la cadena productiva (CEPAL, FAO, e IICA, 2019-2020): una experiencia que la industria camaronera ecuatoriana ha llevado a cabo (Ministerio de Producción, 2020).

Los datos de la Encuesta Tecnológica (INEC, 2018) arrojan que la conectividad de la zona rural a nivel nacional fue del $16.1 \%$ en el 2012 y que subió al $49.1 \%$ en el 2018. "La fractura digital entre territorios rurales rezagados y los sectores urbanos más adelantados es todavía muy alta" (CEPAL, FAO e IICA, 2019-2020). Vista la dispersión de las llamadas "zonas blandas", las inversiones privadas, por un lado, no resultan rentables y, por el otro, los habitantes de las zonas rurales no están en condiciones de pagar por el uso de ese servicio tecnológico.

Se ha convertido en un factor clave la inversión gubernamental o privada en telecomunicaciones para el sector rural, el cual, pese a la dispersión de sus "zonas blandas", ha conseguido la interconexión de los productores con todos los actores de la cadena de valor; a la par, una formación humana y profesional en una universidad a la vanguardia de las tecnologías digitales contribuirá grandemente al levantamiento del sector.

Resulta preponderante contar con una institución de educación superior que maneje criterios de inclusión, calidad y pertinencia para incrementar la agricultura y la ganadería, tecnificar y optimizar procesos, diversificar la producción, resolver logísticas de almacenamiento y distribución, comercializar bienes y servicios, cuidar el medio ambiente, adoptar estrategias de mitigación y adaptación ante el cambio climático, a fin de combatir la pobreza rural, garantizando así la seguridad y soberanía alimentaria dentro de los territorios de los cantones de Daule, Salitre y Santa Lucía (provincia del Guayas).

En la siguiente sección se presentarán la metodología y las actividades relacionadas con la oferta y demanda existentes.

\section{Metodología}

La metodología que se utilizó es la investigación cualitativa por recolección de datos a través de las herramientas siguientes:

1) Observaciones directas.

2) Un cuestionario - formularios en línea de Google-, con 6 preguntas cerradas y 4 abiertas y de opción múltiple, destinado a una muestra dirigida o no probabilística, denominada también "muestras por conveniencia", compuesta por los casos que se tienen a mano (Battaglia, 2008a, citado por Hernández et al. 2014). La elección de esta técnica obedeció a que, como se estaba en época de la pandemia del coronavirus, las muestras se encontraban próximas y convenientemente disponibles para el investigador (Roque et al., 2018). El cuestionario se aplicó entre el 18 de marzo y el 27 de abril de 2021 a jóvenes entre los 16 y 24 años, residentes de Daule, Salitre y Santa Lucía, a objeto de conocer su grado de interés frente a la propuesta de crear una Universidad con carreras agropecuarias para los tres cantones.

3) Fuentes secundarias: textos, programas o planes de los gobiernos de turno, información sobre los cantones en reconocidos diarios, plataformas de organismos oficiales, artículos de pares latinoamericanos $\mathrm{y}$, como principal fuente para 
complementar los resultados de la investigación, el Plan Nacional de Desarrollo 2017-2021.

La estrategia de investigación fue el estudio de caso, por cuanto le permite al investigador la exploración en profundidad de un programa, evento, actividad o proceso, ya sea a uno o más sujetos. Los casos son limitados por el tiempo y actividad (Creswell, 2009).

\section{Oferta actual de carreras en los tres cantones}

Antes de revisar la oferta de los 3 cantones, se hace preciso examinar la oferta académica nacional vigente en universidades, escuelas politécnicas e institutos técnicos y tecnológicos por campo de conocimiento. En Agricultura, silvicultura, pesca y veterinaria existen 164 ofertas, pero solamente 5 en Agricultura (DGNI, SNIESE, SIIEES, 2021).

En Ecuador hay 60 universidades y escuelas politécnicas: 33 públicas, 19 particulares autofinanciadas y 8 particulares cofinanciadas; asimismo, 286 institutos técnicos y tecnológicos: 140 públicos y 146 particulares.

La presente investigación ha advertido un ligero repunte en el desempeño de los Gobiernos Autónomos Descentralizados (GAD): en el Cantón Daule, se ha celebrado un convenio con el Instituto Tecnológico Argos, que, dentro de su oferta académica, ofrecerá la carrera de Producción Agrícola, lo cual beneficiará a los jóvenes de los territorios de este estudio (Municipalidad de Daule, 2020).

En la Tabla 3, aparecen las ofertas académicas públicas (1) y privadas (3) de los centros e institutos superiores de los tres cantones — nótese la ausencia de licenciaturas o ingenierías universitarias en todas las carreras-.

\section{Tabla 3}

Centros e Institutos tecnológicos de Daule, Santa Lucía y Salitre

\begin{tabular}{|c|c|c|}
\hline Cantón & Centros de estudios & Carreras \\
\hline \multirow[t]{3}{*}{ DAULE } & $\begin{array}{l}\text { Tecnológico Juan Bautista Aguirre } \\
\text { Público }\end{array}$ & $\begin{array}{l}\text { Seguridad y Transporte Terrestre; } \\
\text { Seguridad y Prevención de } \\
\text { Riesgos Laborales; Medición y } \\
\text { Monitoreo Ambiental; Seguridad } \\
\text { Ciudadana y Orden Público; } \\
\text { Desarrollo de Software; } \\
\text { Contabilidad; Ensamblaje y } \\
\text { Mantenimiento de Equipos. }\end{array}$ \\
\hline & $\begin{array}{l}\text { Tecnológico Argos } \\
\text { Privado }\end{array}$ & 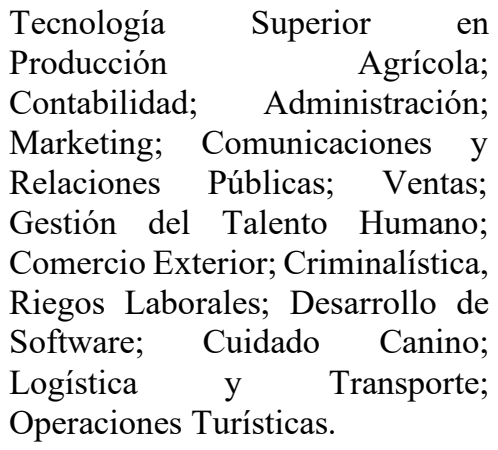 \\
\hline & $\begin{array}{l}\text { Tecnológico Rey David } \\
\text { Privado }\end{array}$ & $\begin{array}{l}\text { Análisis de Sistema; Planificación } \\
\text { y Gestión de Tránsito. }\end{array}$ \\
\hline
\end{tabular}




\begin{tabular}{|c|c|c|}
\hline Cantón & Centros de estudios & Carreras \\
\hline \multirow{5}{*}{ SALITRE } & Centro a distancia de la & Trabajo Social y Desarrollo \\
\hline & Universidad Católica & Humano; Ingeniería en \\
\hline & Santiago de Guayaquil & $\begin{array}{l}\text { Contabilidad y } \quad \text { Auditoría; } \\
\text { Ingeniería en Marketing; Turismo }\end{array}$ \\
\hline & Privado & $\begin{array}{l}\text { y Hotelería; Derecho y } \\
\text { Administración. }\end{array}$ \\
\hline & $\begin{array}{l}{ }^{1} \text { Creación de un instituto técnico de } \\
\text { educación superior. }\end{array}$ & $\begin{array}{l}\text { Proyectos de agroturismo o del uso } \\
\text { del cuero. }\end{array}$ \\
\hline
\end{tabular}

SANTA LUCÍA Ninguno Ninguno

Nota. ${ }^{1}$ Propuesta del alcalde Salitre (tomado del sitio Web de Tecnológicos).

En la Tabla 4, se presentan las 36 instituciones educativas que brindan servicio hasta el bachillerato. He aquí el nicho por atender en lo referente a la educación superior de Daule, Santa Lucía y Salitre.

\section{Tabla 4}

Instituciones educativas hasta bachillerato de Daule, Santa Lucía y Salitre

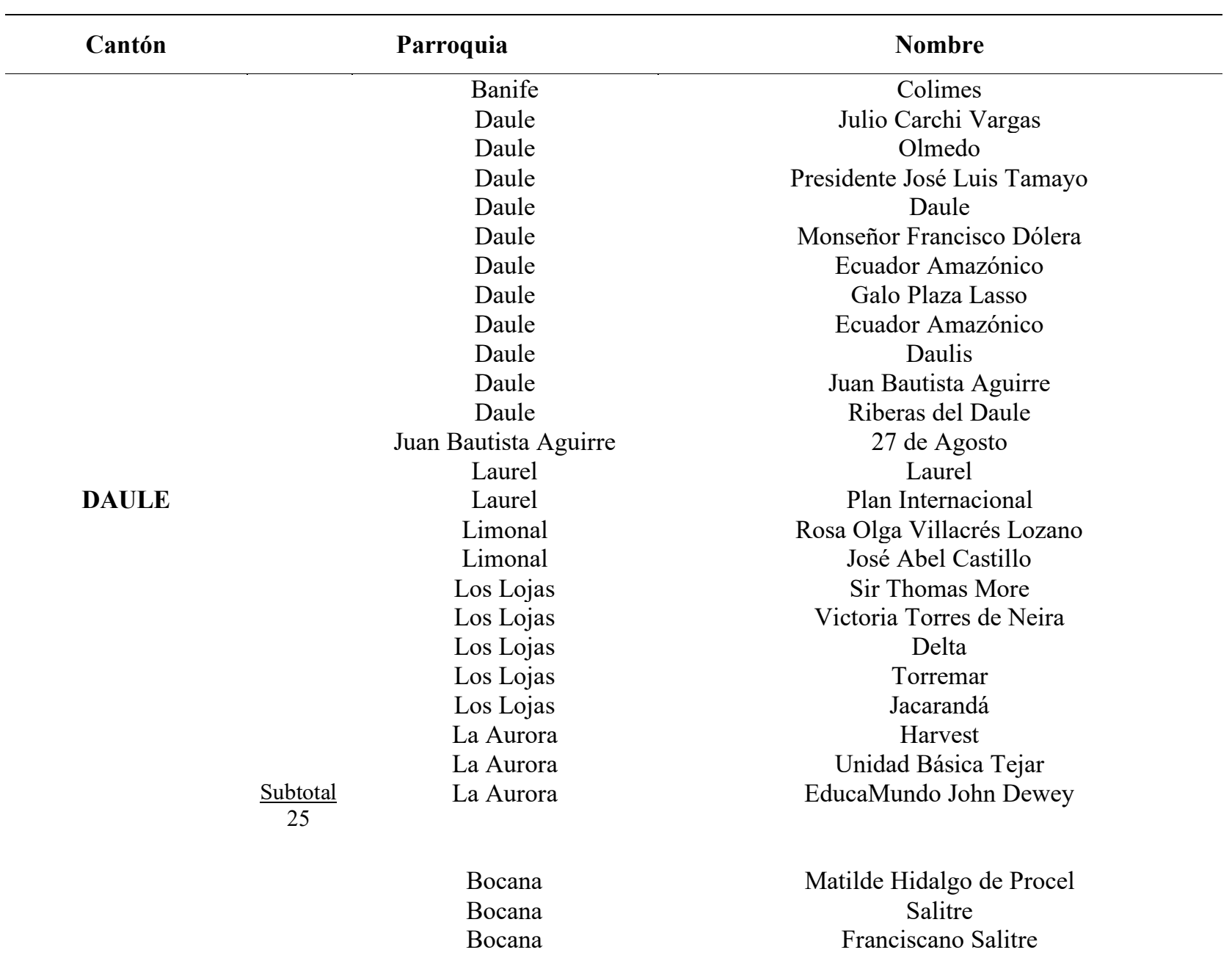




\begin{tabular}{|c|c|c|}
\hline Cantón & Parroquia & Nombre \\
\hline SALITRE & $\begin{array}{c}\text { Bocana } \\
\text { General Vernaza } \\
\text { General Vernaza } \\
\text { La Victoria (Ñauza) } \\
\text { Junquillal }\end{array}$ & $\begin{array}{l}27 \text { de Noviembre } \\
\text { General Vernaza } \\
\text { Zenón Vélez Viteri } \\
\text { La Victoria } \\
\text { Junquillal }\end{array}$ \\
\hline \multirow[t]{2}{*}{ SANTA LUCÍA } & $\frac{\text { Subtotal }}{3}$ & $\begin{array}{c}\text { Porvenir } \\
\text { Santa Lucía } \\
\text { Cabuyal }\end{array}$ \\
\hline & Total de instituciones educativas: & 36 \\
\hline
\end{tabular}

Nota. Tomado de los registros administrativos del Ministerio de Educación.

\section{Demanda potencial de jóvenes que habitan en los tres cantones}

Para determinar la demanda, se seleccionaron dos grupos en función de las edades rango determinadas por el INEC - Censo de Población y Vivienda 2010: de 15 a 19 años y de 20 a 24 años, posibles edades anteriores y posteriores a la culminación del Bachillerato General Unificado en las áreas urbanas y rurales de Daule, Salitre y Santa Lucía. Se llegó a un total 36 127 jóvenes.

\section{Demanda efectiva}

Un total de 3847 graduados, en instituciones de sostenimiento fiscal o particular, pertenecientes a cantones y parroquias urbanas y rurales, constituyen la demanda efectiva y son un subconjunto de la demanda potencial anteriormente establecida. La cifra se obtuvo a partir del número de bachilleres de Daule, Santa Lucía y Salitre que se graduaron en el periodo 2019-2020 (Ministerio de Educación, 2021).

En la variable "Asiste a un establecimiento de enseñanza regular", elaborada a partir de los datos obtenidos en la red REDATAM del INEC-Censo de Población y Vivienda 2010, y que se aplicó a los dos grupos de edades arriba mencionados, resulta significativo el porcentaje de NO asistencia de los jóvenes de Santa Lucía y Salitre frente al 57 \% de jóvenes de Daule, entre 15-19 años, que sí asisten (ver Figura 2).

\section{Figura 2}

Asisten y no asisten a un establecimiento enseñanza regular

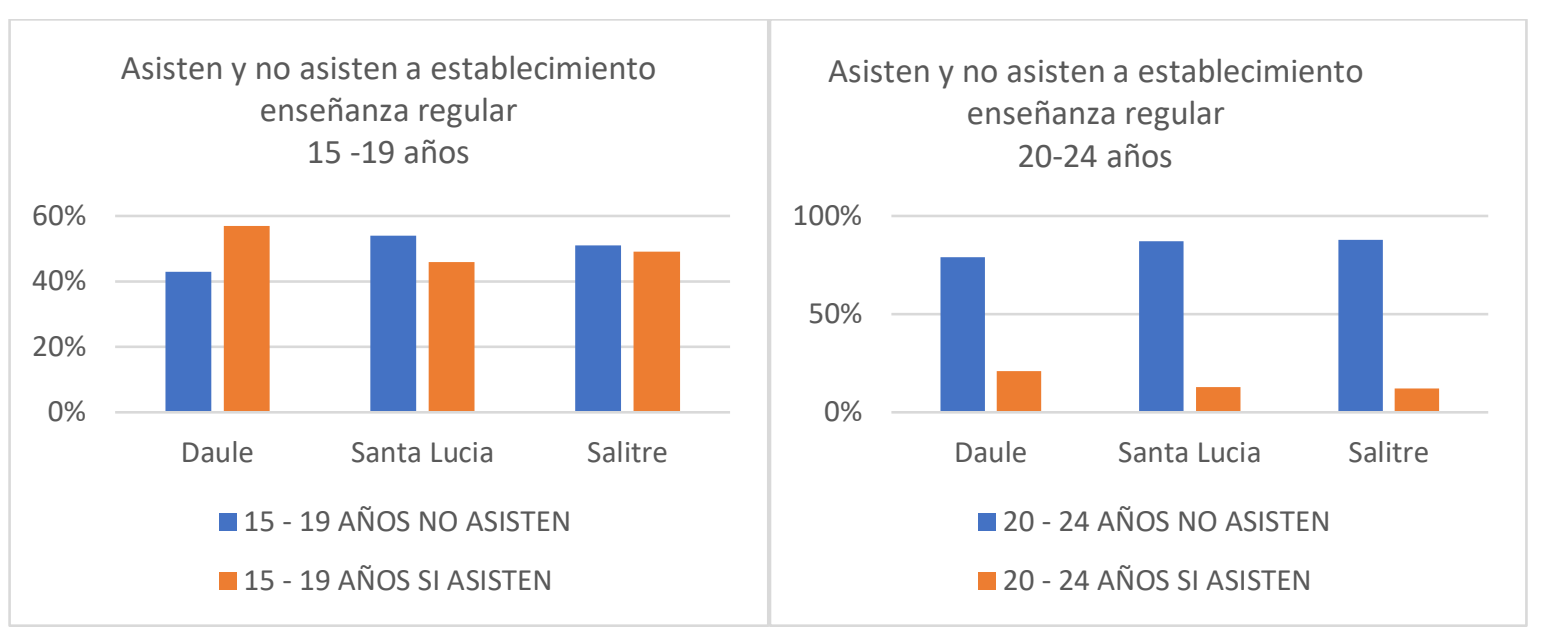

Nota. Tomado del INEC - Censo de Población y Vivienda 2010. 
A fin de explorar con mayor profundidad esta situación de NO asistencia de los jóvenes a un establecimiento de enseñanza regular, y dada la imposibilidad de obtener una muestra aleatoria, se reformularon las "muestras por conveniencia" con un trabajo previo de criterios de selección, como Residir en área rural o urbana de Daule, Salitre o Santa Lucía y Edad: de 16 a 24 años.

En ese sentido, se encuestaron a 200 jóvenes utilizando formularios de Google por la red WhatsApp, entre el 18 marzo y el 27 abril de 2021.

\section{Resultados}

Los participantes provienen en un $46 \%$ de Daule, un $31 \%$ de Santa Lucía y un $23 \%$ de Salitre (ver Figura 3). El 67,5\% son mujeres y el 32,5\%, hombres.

\section{Figura 3}

\section{Cantón de residencia}

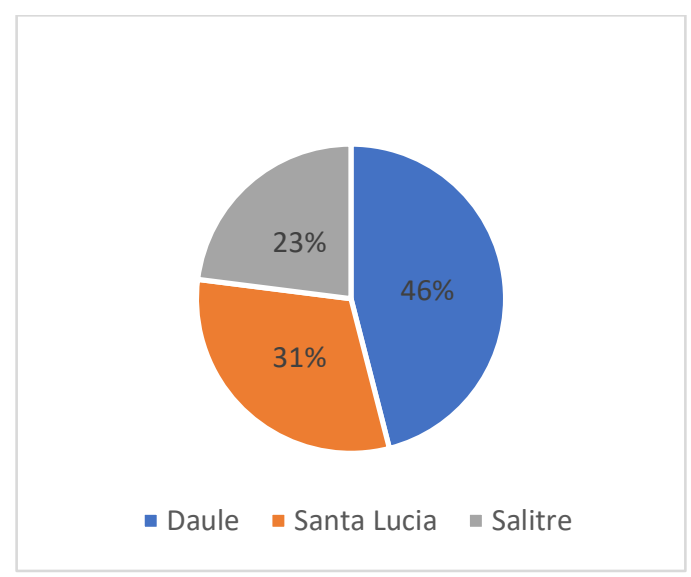

Quienes más respondieron el cuestionario están entre los 16 y 17 años, cursan los últimos años de Bachillerato y son potenciales postulantes a la Universidad Agropecuaria.

\section{Figura 4}

Jóvenes de 16 a 24 años encuestados

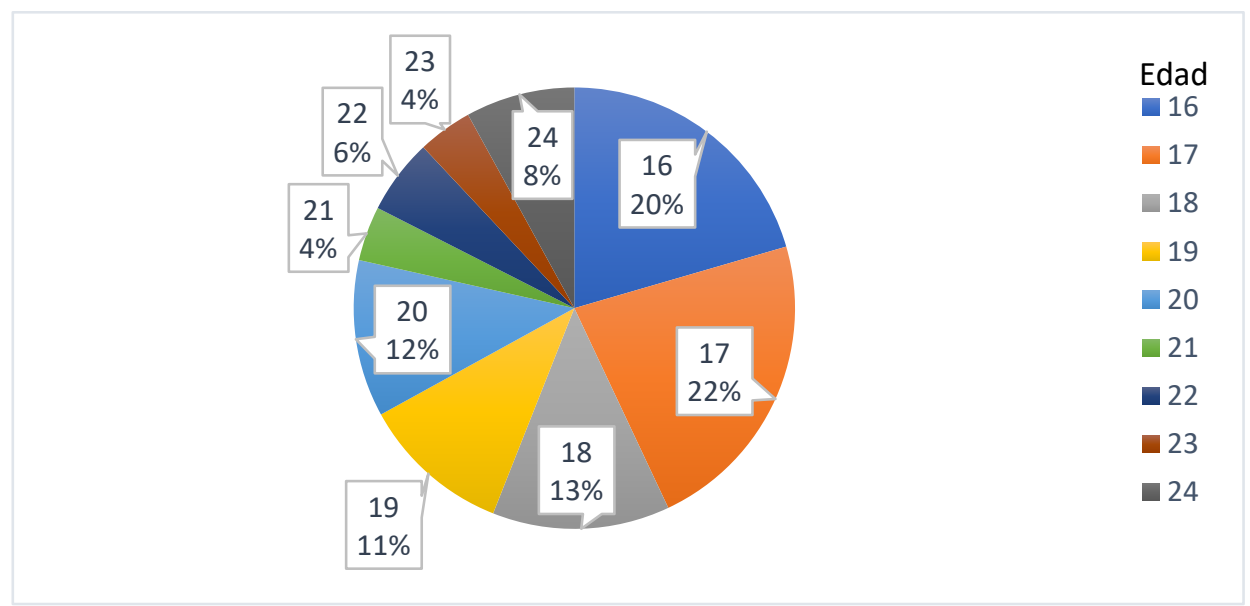


El $55 \%$ de los encuestados Sí estudia; de este grupo, el $60.9 \%$ cursa Bachillerato General en las siguientes especialidades: $45 \%$ Ciencias, $45 \%$ Informática, 7 \% Contabilidad y un $3 \%$ en otras. El restante $39.1 \%$ corresponde a los que cursan estudios superiores, y se distribuye así: un $60 \%$ está en carreras del área comercial y ciencias económicas y un $9 \%$, en carreras de informática — porcentajes más representativos-.

Desde sus lugares de residencia, el $47 \%$ se traslada a la Universidad de Guayaquil, el $35 \%$ asiste al Instituto Tecnológico Juan Bautista Aguirre de Daule, un 9\% se educa en la Universidad Estatal de Milagro y el restante 9\% en otros centros de educación.

El $45 \%$ de los encuestados NO estudia; de este grupo, el $41 \%$ habita en Salitre; el 19 $\%$, en Santa Lucía, y el $40 \%$, en Daule. Representan el $82 \%$ y el $86 \%$ del área rural de Santa Lucía y Salitre, respectivamente; por su parte, de los encuestados de Daule que no estudian, el $39 \%$ reside en el área rural y el $61 \%$, en la urbana.

\section{Figura 5}

\section{Encuestados de Daule, Santa Lucía y Salitre que no estudian}

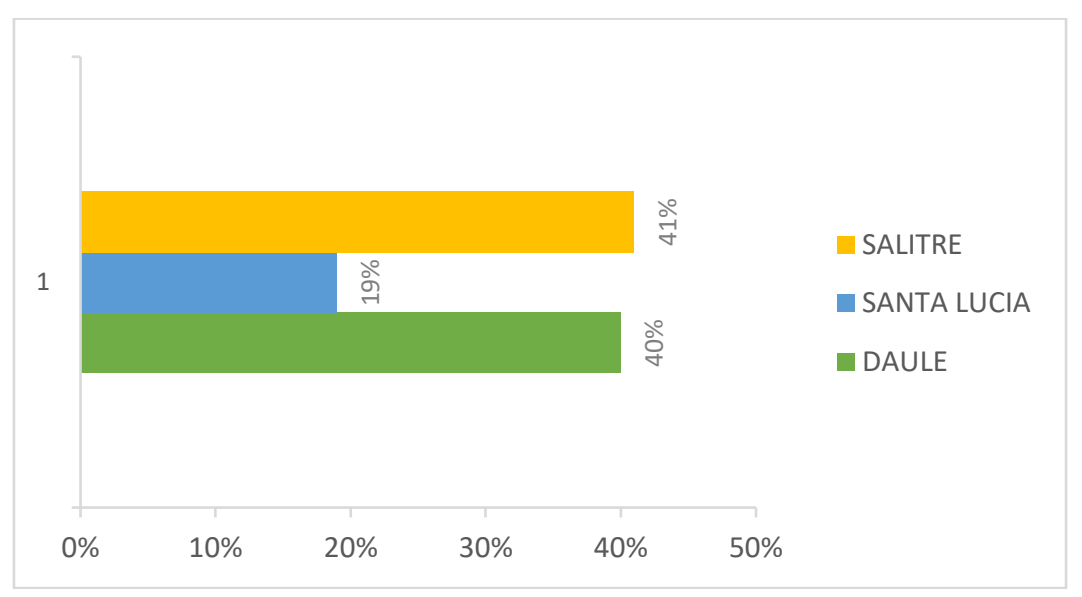

A los jóvenes encuestados que no estudian, elementos clave de esta investigación, se les presentó el proyecto de creación de la Universidad Agropecuaria, haciéndoles preguntas abiertas. Los resultados se presentan en la Figura 6.

La mayor parte de los factores endógenos encontrados esperan una acción y una respuesta que se pueden dar a la luz de los numerales 4.5.6. y 7. Pese a que los jóvenes que no estudian están conscientes de su limitada preparación, sus deseos de superación son grandes; pese a sus adversas condiciones familiares, llevan consigo una esperanza: prepararse, ofrecer una mejor calidad de vida a su familia y la comunidad, aportar al agro, ayudar a las personas sin estudio, contribuir en la educación...

Ante la primera pregunta: ¿Te gusta el proyecto de crear una universidad agropecuaria en un espacio rural, con clases prácticas y carreras relacionadas con la agricultura, entre los cantones Daule, Salitre y Santa Lucía? Un 99,5 \% respondió que sí, lo cual demuestra el impacto claro y positivo que tendría el proyecto, y un $0.5 \%$, que no.

Con el fin de conocer la inclinación de los jóvenes hacia la oferta académica nacional vigente en universidades, escuelas politécnicas e institutos técnicos y tecnológicos, se les preguntó sobre su disposición para estudiar una carrera con título de grado en 4-6 años, perteneciente al área 1 (Ingenierías). Un $94 \%$ se mostró favorable. 


\section{Figura 6}

Jóvenes de Daule, Santa Lucía y Salitre que no estudian

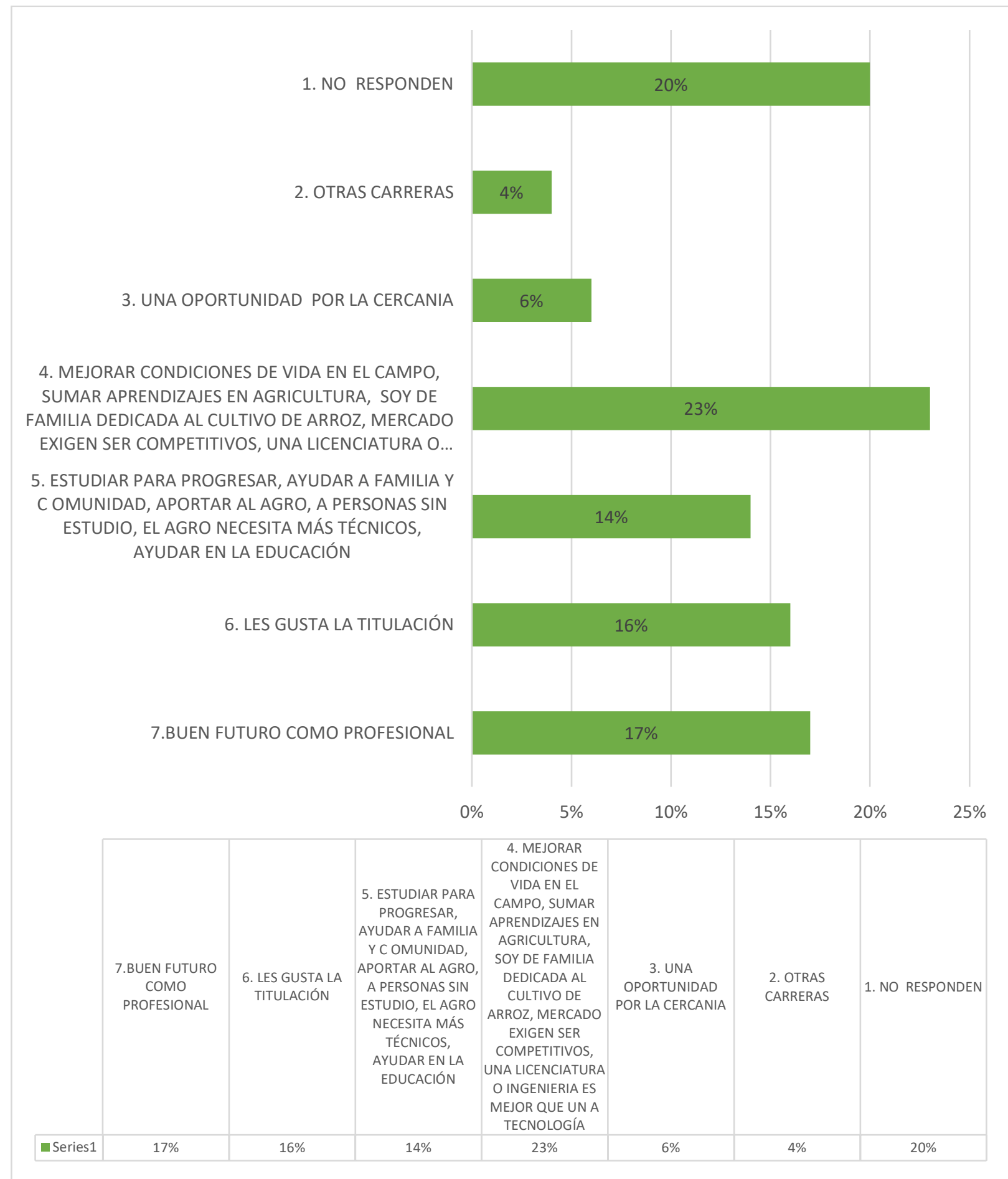

Respecto de la consulta: ¿Cuál es el motivo por el que los jóvenes de tu edad, que viven en la zona de Daule, Salitre o Santa Lucía, que se gradúan del colegio, no pueden continuar sus estudios en la universidad? Un 81,5\% adujo motivos económicos; un $66 \%$ alegó que las universidades estaban lejos del lugar donde residían, y, por último, un 40,5\% dio razones de trabajo. 
Según el reporte mensual, con corte hasta mayo de 2021 (DGNI, SNIESE, SIIEES, 2021), las cifras del Plan de Desarrollo del sistema educativo, en cuanto al indicador "No acceso a educación superior de jóvenes entre 18 y 29 años por razones económicas en el área rural", dejan ver que en el 2016, año base, el $26 \%$ no tenía acceso, mientras que, en el 2019, sobrepasaba el $28 \%$.

La tendencia a la subida del indicador fijado por la SENESCYT (Secretaría Nacional de Educación Superior, Ciencia, Tecnología e Innovación - a causa de la pandemia en el 2020 - lleva al convencimiento de que la inversión social en la zona de los tres cantones es justa e imprescindible para reducir los costos de movilización, alimentación y tiempo de los estudiantes.

En relación con lo anterior, donde la falta de recursos económicos se vuelve el impedimento mayor para no asistir a la universidad, y ante la pregunta: ¿Si te ofrecieran una beca parcial para cubrir parte de tus gastos (alimentación, transporte y material bibliográfico) te comprometerías a sacar buenas calificaciones y mantener la beca hasta el final de tu carrera? Un 97,6 \% respondió que sí. Aquí cabe destacar que la voluntad de formarse prevalece sobre los obstáculos.

Habida cuenta de que los jóvenes rurales suelen desertar de los estudios a causa de sus actividades laborales (siembra de arroz, cuidado de animales, cuidado de la hacienda, ayuda a los padres...), se les dio a escoger entre dos franjas horarias: de 07:00 a 12:00 y de 12:00 a 16:00. Un $52 \%$ escogió el horario vespertino.

Desde la promulgación de la Constitución de la República del Ecuador de 2008, la universidad pública es gratuita; sin embargo, objetando ese beneficio, se les preguntó: ¿Cuánto estarías dispuesto a cubrir por el COSTO SEMESTRAL de la carrera que eliges? Un 76,3\% pagaría un valor mínimo semestral de $\$ 50$ a $\$ 100$; un $18,4 \%$ está dispuesto a pagar $\$ 100$ a $\$ 150$, por mantenimiento e instalaciones de la Universidad; el porcentaje restante cubriría un valor mayor a $\$ 200$.

Por último, y para conocer qué otros aspectos del proyecto podrían interesar a los jóvenes, se les consultó: ¿Qué servicios esperarías recibir de la Universidad Agropecuaria además de la educación? Un 71,5\% se inclinó por la facilidad de transporte - se lo concibe como un servicio que debe gestionar la propia universidad-; un 57,5 \% seleccionó la facilidad de salas de estudios; un 53,1\% está interesado en tener un club de lenguas extranjeras. Detrás de esas demandas late el empuje y el entusiasmo por hacer realidad el proyecto a corto y mediano plazo.

\section{Conclusiones}

El Ministerio de Educación debe iniciar un trabajo más ejecutivo en los currículos, desde la educación inicial hasta la media, con criterios de relevancia y pertinencia social, con una fuerte apuesta hacia la producción local y regional, con una visión productiva y emprendedora que reconozca las bondades y fortalezas del hábitat como base para la vocación y proyección profesional de niños y jóvenes.

Quienes cursan el bachillerato general — dentro de la muestra analizada — se decantan por especialidades como informática, ciencias o contabilidad. Salvo contadas excepciones, quienes cursan ciencias vislumbran un panorama prometedor, futuras fuentes de trabajo o estudio no acordes con la realidad donde viven; algo que está muy lejos de atenuar los factores endógenos y exógenos de los tres cantones. 
Quienes cursan estudios superiores - dentro de la muestra analizada - en carreras comerciales, de Ciencias Económicas o de Informática, en universidades o institutos tecnológicos, puede que migren a otras ciudades en busca de mejores ofertas laborales (fuga de cerebros) y que en muchos casos no vuelvan. Los residentes rurales de la zona han optado por carrera no agrícolas, lo cual pone en riesgo la renovación generacional en la agricultura y el cumplimiento de los ODS.

Existe una alta oferta académica de carreras en áreas comerciales tanto en institutos tecnológicos, que funcionan dentro los cantones, como en universidades cercanas a su lugar de residencia (Guayaquil y Samborondón); una mediana oferta académica de carreras agropecuarias en las universidades de Vinces, Babahoyo, Guayaquil y Milagro, menos cercanas a su lugar de residencia, y una baja oferta académica de carreras con perfil agropecuario en los institutos tecnológicos de Daule.

La puesta en marcha de una universidad agropecuaria supone la formación de profesionales con altos conocimientos sobre las actividades productivas al objeto de atenuar los factores endógenos y exógenos. Resulta ineludible la implementación de políticas públicas con el fin de asegurar el desarrollo rural de los tres cantones.

La búsqueda bibliográfica de esta investigación puso de manifiesto la existencia de políticas públicas encaminadas al desarrollo rural procedentes de estudios, ya sea de organismos gubernamentales, ya sea de organizaciones no gubernamentales. Lo único que hace falta es la voluntad política: acciones y recursos de los gobiernos de turno para, estratégicamente, seguir la ruta ya trazada.

Deviene imperiosa la concreción de la Universidad Agropecuaria con fondos estatales. Como plan B, se recomienda su financiamiento con fuentes externas: préstamos o donaciones extranjeros, inversiones nacionales o foráneas, convenios o potenciación de la oferta con otras universidades nacionales o extranjeras públicas o privadas, para crear, ofrecer y diseñar carreras con criterios de pertinencia geográfica y de impacto económico y social, tales como las que se citan a continuación: Ingeniería agrícola y pecuaria, Ingeniería en Alimentos y Procesos, Administración de Empresas Agropecuarias, Ingeniería en Logística, Distribución y Almacenamiento, Ingeniería en Medio Ambiente y Clima.

La creación de la Universidad Agropecuaria ha de ir a la par de una fuerte inversión social, desde el Estado, en la capacitación y educación rural, a través de asignaciones a las universidades tanto para sus gastos operativos como para subsidios específicos en favor de jóvenes universitarios de escasos recursos originarios de esas áreas rurales.

Una segunda investigación deberá centrarse en determinar la estructura administrativoacadémica de la Universidad Agropecuaria.

\section{Referencias}

Banco Mundial (11 de noviembre de 2016). https://www.bancomundial.org/es/news/feature/2016/11/11/cuatromaneras-de-combatir-pobreza-con-la-agricultura?CID=ECR_TT_WorldBank_ES_EXT

Banco Mundial (7 de marzo de 2017). Mujeres en la agricultura: las agentes del cambio en el sistema alimentario mundial. https:/www.bancomundial.org/es/news/feature/2017/03/07/women-inagriculture-the-agents-of-change-for-the-food-system 
Burgos Guerrero, R., Samudio G., M. y Farias B., R. (2011). DIAGNÓSTICO: El territorio del Norte del Guayas y Los Rios. Grupo Dialogo Rural / U. Santa Maria.

Caicedo, E. (2 de junio de 1902). Apuntes Históricos, Geográficos, Biográficos y Estadisticos del Cantón Daule. https://digitalcollections.library.harvard.edu/catalog/990043011340203941

CEPAL, FAO e IICA (30 de diciembre de 2019-2020). Perspectivas de la agricultura y del desarrollo rural en las Américas: una mirada hacia América Latina y el Caribe 2019-2020. Instituto Interamericano de Cooperación para la Agricultura (IICA): https://www.iica.int/es

Constitución del Ecuador (20 de octubre de 2008). Asamblea Ecuador. http://archivobiblioteca.asambleanacional.gob.ec/constituciones-del-ecuador

Contreras, A. C. (2015). Situación de la educación rural en el Ecuador. Guayaquil: Centro Latinoamericano para el desarrollo rural.

COOTAD (10 de febrero de 2011). Código Orgánico de Organización Territorial, Autonomía y Descentralización.

Corvalán, J. (1 de julio de 2006). Educación para la población rural en siete países de América Latina. Síntesis y análisis global de resultados por países. Revista Colombiana de Educación, (51), 40-79. https://doi.org/10.17227/01203916.7684

Creswell, J. W. (2009). Research Design, Qualitive, Quantitative and Mixed Methods Approaches. SAGE Publications.

DGNI, SNIESE, SIIEES. (21 de abril de 2021). Estadística de Educación Superior, Ciencia, Tecnología e Innovaciión. https://siau.senescyt.gob.ec/estadisticas-de-educacion-superior-ciencia-tecnologia-einnovacion/?doing_wp_cron=1629947380.8285670280456542968750

El Comercio (8 de noviembre de 2019). Servicios básicos, un desafío de Salitre. https://www.elcomercio.com/actualidad/servicios-basicos-cobertura-salitre-municipio.html

El Comercio (7 de enero de 2019). Santa Lucía, la tierra de la cultura Chonanis y Daulis. https://www.elcomercio.com/tendencias/santa-Lucía-cultura-chonanis-guayas.html

El Telégrafo (14 de septiembre de 2014). El banquero Francisco Urbina Jado y algunos datos de su influencia. https://www.eltelegrafo.com.ec/noticias/regional/1/el-banquero-francisco-urbina-jado-y-algunos-datosde-su-influencia

El Universo (24 de noviembre de 2002). Salitre: Montubio, fecundo y turístico. https://www.eluniverso.com/2002/11/24/0001/12/5B16FFB7815248F991CF0A6C704E9B51.html

ESPAC (30 de diciembre de 2019). INEC. Encuesta de Superficie y Producción Agropecuaria Continua. https://www.ecuadorencifras.gob.ec/estadisticas-agropecuarias-2/

FAO (2016). Organización de las Naciones Unidas para la Alimentación y Agricultura. http://www.fao.org/3/i5570s/i5570s.pdf

GAD Cantón Daule (29 de agosto de 2021). PDYOT Cantón Daule 2015-2025. https://www.daule.gob.ec/web/guest/planes

GAD Cantón Salitre (2020). GAD Municipal de Salitre. https://www.salitre.gob.ec/gad-municipal-de-salitre/

GAD Cantón Santa Lucía (26 de agosto de 2021). PDYOT Cantón Santa Lucía 2021-2032. http://www.gadsantaLucía.gob.ec/

GAD El Laurel (12 de noviembre de 2015). Plan de Desarrollo y Ordenamiento Territorial de la Parroquia El Laurel 2015-2025, PDOT. https://es.wikipedia.org/wiki/El_Laurel 
Gajardo, M. (6 de octubre de 2014). Revista Iberoamericana de Evaluación Educativa. https://www.redalyc.org/pdf/4136/413635245003.pdf

Hernández Sampieri, R., Fernández Collado, C. y Baptista Lucio, M. (2014). Metodología de la Investigación. McGraw-Hill / INTERAMERICANA EDITORES, S.A. DE C.V.

Herrera, D. y Rivera, J. (diciembre de 2020). La educación rural: Un desafio para la transición a la educación superior. https://scielo.conicyt.cl/scielo.php?pid=S0718-

$51622020000300087 \&$ script $=$ sci_arttext_plus\&tlng=es\#B9

INEC (30 de diciembre de 2018). ECUADOR EN CIFRAS . https://www.ecuadorencifras.gob.ec/tecnologias-dela-informacion-y-comunicacion-tic-2018/

INEC (2 de diciembre de 2010). Resultados del Censo 2010 de Población y Vivienda. Proyección de la poblacion, por años calendario, según cantones. https:/www.ecuadorencifras.gob.ec/informacioncensal-cantonal/

Lavell , A. y Witkowsky, K. (2016). Gestión del riesgo y adaptación de la agricultura y el medio

rural al cambio climático: Aportes técnicos. Instituto Interamericano de Cooperación para la Agricultura (IICA).

https://repositorio.iica.int/bitstream/handle/11324/2993/BVE17068911e.pdf;jsessionid=95350BF8ABF A97FD02D578E5F10793F6?sequence=1

LOES (12 de cctubre de 2010). Consejo de Educación Superior. https://www.ces.gob.ec/

Ministerio de Agricultura, Ganaderia, Acuacultura y Pesca. MAGAP (2016). La política agropecuaria ecuatoriana: Hacia el desarrollo rural social sostenible 2015-2025. http://www.competencias.gob.ec/wp-content/uploads/2017/05/01PPP2016-POLITICA01.pdf

Ministerio de Educación (18 de febrero de 2021). Ministerio de Educación. https://educacion.gob.ec/estadisticaseducativas/

Ministerio de Producción (24 de noviembre de 2020). Camarón ecuatoriano, primero en el mundo en garantizar completa trazabilidad de su producción. https://www.produccion.gob.ec/camaronecuatoriano-primero-en-el-mundo-en-garantizar-completa-trazabilidad-de-su-produccion/

Municipalidad de Daule (4 de diciembre de 2020). Daule Capital Arrocera del Ecuador.

https://daule.gob.ec/ja/busqueda?q=convenio

Nieuwkoop, M. V. (3 de diciembre de 2019). Banco Mundial. https://blogs.worldbank.org/es/voces/quesignifica-ser-agricultor-en-el-siglo-XXI

Obando, E. E. (2016). Desarrollo Rural Territorial: ¿El mejor recurso para resolver las problemáticas de las poblaciones rurales costarricenses? Análisis del periodo 1990-2014. Centro de Investigaciones Históricas de América Central (CIHAC).

Observatorio Social del Ecuador (19 de febrero de 2018). Situación de la niñez y adolescencia en el Ecuador, una mirada a través de los ODS. https://www.unicef.org/ecuador/informes/situaci\%C3\%B3n-de-lani\%C3\%B1ez-y-adolescencia-en-el-ecuador

Ochoa Arias , P. y Enríquez García, M. J. (2017). La regularización predial en el Ecuador y su relación con el incremento del acceso al crédito. Memorias y boletines de la Universidad del Azuay, 1(XVI) 221-231. http://revistas.uazuay.edu.ec/index.php/memorias/article/view/67

PNUD (23 de febrero de 2016). Programa de las Naciones Unidas para el Desarrollo. https://www.undp.org/content/undp/es/home/librarypage/poverty-reduction/undp-support-to-theimplementation-of-the-2030-agenda.html 
Rodríguez-González, S., Schneider, S. y Coelho-de-Souza, G. (16 de junio de 2015). RECONEXIÓN PRODUCCIÓN-CONSUMO: CAMBIO PARA LA SEGURIDAD ALIMENTARIA Y NUTRICIONAL Y EL DESARROLLO RURAL. https://revistas.ucr.ac.cr/index.php/agromeso/article/view/19332/19569

Roque Herrera, Y., Gagas González, C., Herrera Molina, A., Salazar Granizo, Y., Betancourt Jimbo, C. y Figueredo Villa, K. (2018). Pertinencia de la formación académica de enfermería.Universidad Nacional de Chimborazo. Ecuador. Educación Médica, 19(52) 73-78.

Sarabia-Altamirano, G. (enero de 2016). La vinculación universidad-empresa y sus canales de

interacción desde la perspectiva de la academia, de la empresa y de las politicas públicas. https://www.redalyc.org/articulo.oa?id=441944752002

SENPLADES (22 de septiembre de 2017). Plan Nacional de Desarrollo 2017-2021. Toda una Vida. https://www.planificacion.gob.ec/plan-nacional-de-desarrollo-2017-2021-toda-una-vida/

Villarreal, F. G. (2017). Inclusión financiera de pequeños productores rurales. CEPAL-FIDA. 